\title{
Crashworthiness and Impact Energy Absorption Study Considering the CF/PA Commingled Composite Processing Optimization
}

\author{
Ricardo Mello Di Benedetto ${ }^{a, b *}$, Olívia de Andrade Raponi ${ }^{a}$, Diego Morais Junqueira ${ }^{a}$, \\ Antonio Carlos Ancelotti Junior ${ }^{a}$ \\ anstituto de Engenharia Mecânica, Universidade Federal de Itajubá - UNIFEI, Av. BPS, 1303, Itajubá, \\ $M G$, Brazil \\ ${ }^{b}$ Center for Composite Materials (CCM), University of Delaware - UDEL, 101, Academy Street - \\ Newark, DE 19716, USA
}

Received: August 29, 2017; Revised: December 11, 2017; Accepted: December 13, 2017

\begin{abstract}
The processing of the thermoplastic composites can cause matrix thermo-oxidative degradation. Understanding the level of thermo-oxidative degradation, as well as the thresholds of temperature and processing time, allows the manufacture of high performance composites with higher crashworthiness. This study evaluated the matrix thermo-oxidative degradation by Friedman's isoconversional kinetic model to a carbon fiber/polyamide (CF/PA) commingled fabric. In addition, the CF/PA commingled composite was manufactured by consolidation under pressure at $240^{\circ} \mathrm{C}, 250^{\circ} \mathrm{C}, 260^{\circ} \mathrm{C}, 270^{\circ} \mathrm{C}$ and $280^{\circ} \mathrm{C}$ to observe the influence of the matrix thermo-oxidative degradation on its energy absorption capacity. Impact test and compression after impact (CAI) determined the energy absorbed by the $\mathrm{CF} /$ PA commingled composite at different processing temperatures. The results demonstrated that the matrix thermo-oxidative degradation affected the energy absorption capacity of the CF/PA composite when the processing temperature exceeded $260^{\circ} \mathrm{C}$, which is in accordance with the prediction of the degradation study. Therefore, the optimal processing cycle occurs at $260^{\circ} \mathrm{C}$ for $20 \mathrm{~min}$. When it processed in temperatures above $260^{\circ} \mathrm{C}$, the $\mathrm{CF} / \mathrm{PA}$ commingled composite reduces in $0.14 \mathrm{~J} /{ }^{\circ} \mathrm{C}$ the energy absorption ability due to the matrix degradation in high temperatures, leading to a considerable reduction on crashworthiness and its performance.
\end{abstract}

Keywords: Energy absorption, CF/PA commingled composite, processing optimization.

\section{Introduction}

Over the last years, the use of composite materials in structural parts on the automobilist industry has grown rapidly. This use implies directly in lightness of automobiles and improving certain features, such as corrosion resistance, impact cushion, noise attenuation and part consolidation ${ }^{1}$. Among several composite materials compositions, carbon and glass fiber reinforced polymers with thermosetting matrices are mainly used in aeronautic and automotive industries ${ }^{2,3}$, due to their high specific stiffness and strength. However, reinforced thermoplastics are gaining industry attention due to their recyclability and to the possibility of manufacturing parts directly from the raw materials, offering an excellent cost-performance ratio ${ }^{4}$. Currently, the thermoplastic matrix mostly used in automotive industries are polypropylene (PP) ${ }^{5}$, but other commercial and not yet exhaustively investigated options are polyamides (PA) and polyesters ${ }^{6}$.

In addition to the features named above, automobile parts also demand high energy absorption capability, in order to provide both nearby components protection and human safety improvements. The energy absorption depends on many parameters, such as fiber and matrix types, processing conditions, fiber volume fraction and testing speed. Therefore,

*e-mail: ricardo@ntc.eng.br any variation on these parameters can cause significant changes in the specific energy absorption of these materials ${ }^{7}$.

Composite materials can be characterized in terms of energy absorption by its crashworthiness and penetration resistance. The first is defined as the ability of a structure to protect its occupants during an impact event and is determined by tests involving controlled failure mechanisms and the maintenance of a gradual degradation in the load profile during absorption. The penetration resistance, on the other hand, is a concept that involves the total energy absorption without allowing the penetration throughout the composite component of a projectile or fragment ${ }^{8}$.

New studies reported in the scientific literature ${ }^{9,10}$ deal with quasi-static tests to evaluate the behavior of thermoplastic composite materials in a crash event. These studies approach the relationship between crashworthiness and energy absorption, even though the energy absorption provided by a composite structure during an impact or compression event is a phenomena not easily predicted due to the complexity of the crush failure mechanisms that occur within the composite material ${ }^{11,12}$. Recent studies ${ }^{13}$ have investigated the damage tolerance of hybrid composites adding thermoplastic toughening agents in order to improve the toughness and energy absorption ability. 
The main challenge associated with the development of an impact resistant composite is to determine the specific features of geometry, materials and processing parameters, enabling greater safety while simultaneously decreasing the component weight, without increasing the overall cost of fabrication and production ${ }^{14}$. Therefore, understanding the mechanism of fracture and the behavior of a composite material in a collision event, considering the influence of thermal degradation on its processing, becomes an important field of study nowadays.

Regarding the raw materials configuration, the commingled technology refers to preforms that contain both reinforcement and matrix yarns in the same fabric, providing easy storage, conformation and malleability ${ }^{15}$, which allows its conformation into the shapes of the flat mold before the consolidation process and in a further rigid structure after processing ${ }^{16}$. The thermoplastic commingled composite has indeed settled as a versatile material, with high-performance and economically attractive for the manufacturing of automobile components ${ }^{17}$. These materials consolidation process results in good compaction of the preform by the proper impregnation and wetting of the reinforcing fibers with the molten polymer matrix, consequently eliminating voids within the material ${ }^{18}$. Some authors focused their studies and works on the processing methods of thermoplastic matrix composites, regarding the consolidation techniques and parameters ${ }^{19-22}$.

Based on this context, the purpose of this study is to evaluate the energy absorption of a carbon fiber/polyamide (CF/PA) thermoplastic commingled composite when submitted to an impact event, followed by a quasi-static compression test - compression after impact $(\mathrm{CAI})^{23}$. The CAI test characterizes the damage that can occur to composite materials if hit by a projectile or if damaged in an accident. This characterization will also take in account the thermal degradation of the composite during the pressure consolidation process.

\section{Experimental Procedures}

\subsection{Materials}

The HTS40 carbon fiber used in the present study is supplied by Toho Tenax(r), and presents a tensile strength and modulus of $4240 \mathrm{MPa}$ and $237 \mathrm{GPa}$, respectively, developed for use as a reinforcement in high performance composites, according to the supplier ${ }^{24}$. The fiber tow size is of $12 \mathrm{k}$.

The polyamide thermoplastic matrix was selected based on its mechanical and thermal properties and also in the fact that it is a material that still presents a great range for crashworthiness properties exploration. The polyamide 6 was supplied by Concordia Manufacturing Co Inc., in a fiber form (Concordia Nylon 6-900/72) to allow the fabrication of the commingled plain weave fabric. According to the supplier, the processing temperature of this material can range from $240-290^{\circ} \mathrm{C}$, and it presents a good price and performance relation, good chemical resistance and high strength ${ }^{25}$.

The CF/PA commingled fabric used on this study was weaved and supplied by Texiglass Ltda.

\subsection{PA thermal analysis and matrix degradation study}

The polyamide 6 (PA6) matrix was characterized regarding its thermal properties by differential scanning calorimetry (DSC) technique, using a Q20 2151 calorimeter with a RCS40 cooling unit, both from TA Instruments. To determine the matrix melting and crystallization temperatures and enthalpies, a $3 \mathrm{mg}$ sample was placed in an aluminum hermetic pan and subject to the thermal program presented on Table 1 .

The analysis was performed under a nitrogen atmosphere, at $30 \mathrm{ml} / \mathrm{min}$ flow rate and the thermal properties of the sample were determinate according to the methodology presented by the ASTM-E1952 26 . The results obtained from DSC analysis were used to guide the selection of a thermal processing cycle for the CF/PA commingled composite.

Table 1. DSC thermal conditions.

\begin{tabular}{|c|c|c|c|c|}
\hline $\begin{array}{l}\text { Thermal } \\
\text { Cycle }\end{array}$ & $\begin{array}{c}\text { Thermal } \\
\text { Process (run) }\end{array}$ & & mal Condition & Justification \\
\hline \multirow{4}{*}{1} & \multirow{2}{*}{1} & Isotherm & $25^{\circ} \mathrm{C}(5 \mathrm{~min})$ & Stabilize the equipment \\
\hline & & Heating Ramp & $25^{\circ} \mathrm{C}-290^{\circ} \mathrm{C}\left(10^{\circ} \mathrm{C} / \mathrm{min}\right)$ & \multirow{3}{*}{$\begin{array}{l}\text { Minimizing previous processing effects } \\
\text { (thermal history) }\end{array}$} \\
\hline & \multirow{2}{*}{2} & Isotherm & $290^{\circ} \mathrm{C}(5 \mathrm{~min})$ & \\
\hline & & Cooling Ramp & $290^{\circ} \mathrm{C}-25^{\circ} \mathrm{C}\left(20^{\circ} \mathrm{C} / \mathrm{min}\right)$ & \\
\hline \multirow{4}{*}{2} & \multirow[b]{2}{*}{3} & Isotherm & $25^{\circ} \mathrm{C}(5 \mathrm{~min})$ & Stabilize the system \\
\hline & & Heating Ramp & $25^{\circ} \mathrm{C}-290^{\circ} \mathrm{C}\left(10^{\circ} \mathrm{C} / \mathrm{min}\right)$ & $\begin{array}{l}\text { Identify the melting endothermic peak and its } \\
\text { enthalpy }\end{array}$ \\
\hline & \multirow{2}{*}{4} & Isotherm & $290^{\circ} \mathrm{C}(5 \mathrm{~min})$ & \multirow{2}{*}{$\begin{array}{l}\text { Identify the crystallization exothermic peak and } \\
\text { its enthalpy }\end{array}$} \\
\hline & & Cooling Ramp & $290^{\circ} \mathrm{C}-25^{\circ} \mathrm{C}\left(20^{\circ} \mathrm{C} / \mathrm{min}\right)$ & \\
\hline
\end{tabular}


The PA matrix degradation behavior was characterized by thermo gravimetric analysis (TGA), performed by a Mettler Toledo AE 240 TG equipment. Friedman's isoconversional kinetic model was chosen to determine the kinetic parameters of the degradation reaction because it is the most common method for polymers and provides straightforward way to evaluate the effective activation energy as a function of the extent of reaction. Therefore, samples of approximately $10 \mathrm{mg}$ of PA were subjected to heating cycles from 0 to $600^{\circ} \mathrm{C}$ at three different heating rates $\left(5,10\right.$ and $\left.15^{\circ} \mathrm{C} / \mathrm{min}\right)$.

The Friedman's model ${ }^{27}$ allows the calculation of the activation energy $\left(E_{a}\right)$, and pre-exponential factor $\left(A_{\alpha}\right)$ by the linearization of the degradation degree rate $\left(\frac{d \alpha}{d t}\right)$, as a function of the temperature inverse $(1 / T)$ plot, for each degree of degradation $(\alpha)$, based on Eq. 1, in which $-\frac{E a}{R T}$ and $\ln A_{\alpha}$ are equivalent to the line's equation slope and intersection, respectively.

$$
\ln \left(\frac{d a}{d t}\right)=\ln A_{a}-\frac{E_{a}}{R T}
$$

Friedman's estimated kinetic parameters can also be combined with the isoconversional method to predict the degradation degree as a function of time for a given temperature, based on Eq.2.

$$
a=A_{a} \exp \left(-\frac{E_{a}}{R T}\right) t
$$

This prediction can then be used to define the thermal process window for the $\mathrm{CF} / \mathrm{PA}$ composite, regarding the time and temperature necessary to provide the softening range of the thermoplastic matrix without reaching its temperature onset damage degradation degrees.

\section{$2.3 \mathrm{CF} / \mathrm{PA}$ commingled fabric configuration}

Even though the carbon and PA6 fibers used in the weaving process are of a commercial type the commingled fabric configuration that involves both of them is not very well-known, leading to the necessity of a prior characterization concerning the fabric configuration and its quality. This characterization was then made by micrographic analyses, performed with a Feldmann Wild FWL-SM7 7.5 stereoscope, an Olympus SZ61 stereoscope and a Zeiss EVO15MA scanning electron microscope.

\subsection{CF/PA commingled composite manufacturing}

The CF/PA commingled composite specimens used for impact test and CAI test were manufactured at $240^{\circ} \mathrm{C}, 250^{\circ} \mathrm{C}$, $260^{\circ} \mathrm{C}, 270^{\circ}$ and $280^{\circ} \mathrm{C}$, considering $20 \mathrm{~min}$ of soak time, previously defined by the degradation study. The Transferpress Wabash 150-2525-2TMX was used to consolidate the 5 layers flat panel samples using aluminum flat plates. The pressure of $0.30 \mathrm{MPa}$ was obtained empirically after a few trials.

\subsection{Impact and CAI tests}

The drop-weight impact test was based on ASTM D7136/ D7136M 20 standard test method. The 6 samples present $152.4 \mathrm{~mm}$ of length, $101.6 \mathrm{~mm}$ of width and $2.76 \mathrm{~mm}$ of thickness. The Dynatup 9200 is an impact device with double column impactor guide mechanism and performed the test considering $0.45 \mathrm{~kg}$ impactor weight, $15.8 \mathrm{~mm}$ impactor shape and $589.3 \mathrm{~mm}$ of drop height.

The energy absorbed by the specimens $(E)$ on the impact test was calculated considering the impact velocity $\left(v_{i}\right)$, impactor displacement $(\delta)$ and time during test $(t)$ as shown in the Eq. 3, 4 and $5^{28}$.

$$
v_{i}=\frac{w_{12}}{t_{2}-t_{1}}+g\left(t_{i}-\frac{(t 1-t 2)}{2}\right)
$$

Where $w_{12}$ is the distance between leading edges of the prongs (lower and upper), $\mathrm{t}_{1}, \mathrm{t}_{2}$ are $\mathrm{t}_{\mathrm{i}}$ are, respectively, the time first (lower) flag prong passes detector, the time second (upper) flag prong passes detector and the time initial contact point.

$$
\delta(t)=\delta_{i}+v_{i} t+\frac{g t^{2}}{2}-\int_{0}^{t}\left(\int_{0}^{t} \frac{F(t)}{m} d t\right) d t
$$

Where, $\delta_{i}$ is the impactor displacement from reference location at time $t=0$ and $F$ is the measured impactor contact force at time $t$.

$$
E(t)=\frac{m\left(v_{i}^{2}-v(t)^{2}\right)}{2}+m g \delta(t)
$$

Where, $m$ is the impactor mass and $g$ is the acceleration due to gravity.

The strain rate $\epsilon^{\dot{\theta}}(t)$ was defined by Eq. $6^{29,30}$.

$\dot{\epsilon}(t)=\frac{d \epsilon}{d t}=\frac{d}{d t}\left(\frac{L(t)-L_{0}}{L_{0}}\right)=\frac{1}{L_{0}} \frac{d L}{d t}(t)=\frac{v(t)}{L_{0}}$

Where, $L_{0}$ is the original specimen length, $L(t)$ is the length at each time $t$ and $v(t)$ is the drop speed. The strain rate defined the dynamic aspect of mechanical testing.

To identify possible defects and voids inside the panel, the specimens were inspected by an ultrasonic C-Scan imaging inspection before the impact test, which served as a quality control and sample exclusion criteria. After impacted, the specimens were inspected ultrasonically to observe the damage caused by the drop-weight event.

The samples, which have been subjected to a quasi-static indentation by the drop-weight impact test, were tested under compressive loading using a stabilization fixture based on ASTM D7137/D7137M-12 ${ }^{31}$, in order to evaluate the compressive residual strength properties of a damaged composite. The CAI test was performed by an Instron 4484 with $300 \mathrm{kN}$ load cell and $12.7 \mathrm{~mm} / \mathrm{min}(0.05 \mathrm{in} / \mathrm{min})$ displacement rate. The area under the load as a function of displacement curve 
can be expressed by Eq.7, which provides the total energy absorption of each specimen tested ${ }^{28,31}$.

$$
E_{C A I}=\int_{0}^{\delta} P d \delta
$$

Where $E_{C A I}$ is the energy absorbed in compression of the composite specimen, $\delta$ is the displacement and $P$ the compressive load.

\section{Results and Discussions}

\subsection{PA matrix thermal analysis and degradation study}

The DSC analysis can reveal the main thermal phenomena occurred during a heating and cooling process. Thus, it guides the selection temperatures during the processing cycle of $\mathrm{CF} / \mathrm{PA}$ commingled composite. Figure 1 shows the result obtained by the DSC analysis.

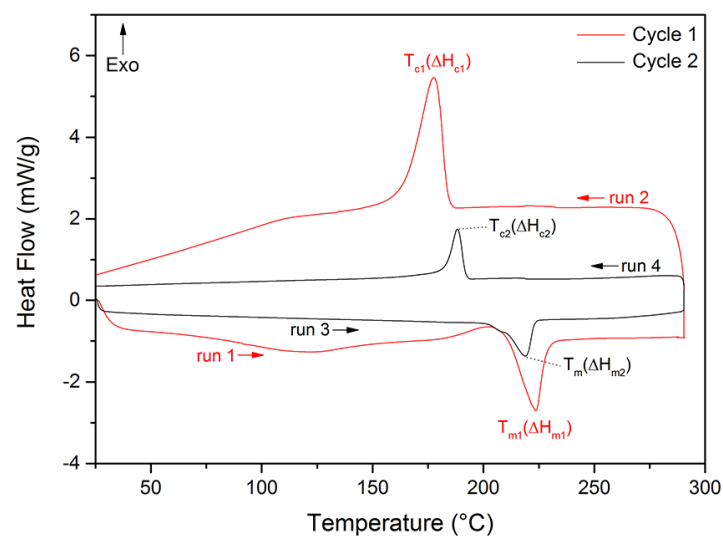

Figure 1. PA matrix DSC thermal analysis. (Bibliographic Source: Author.)

From the first cycle (red line), performed with the purpose of erasing any thermal history of the sample ${ }^{32}$ associated with its previous processing, it can be noticed that the melting of the matrix $\left(T_{m l}\right)$ takes place at $223^{\circ} \mathrm{C}$, with a $59.67 \mathrm{~J} / \mathrm{g}\left(\Delta H_{m l}\right)$ enthalpy value. The exothermic peak presented in run 2 is associated with the crystallization, that occurs at $177^{\circ} \mathrm{C}\left(T_{\mathrm{cl}}\right)$ and has an enthalpy value of $60.32 \mathrm{~J} / \mathrm{g}\left(\Delta H_{c l}\right)$.

The cycle 2 (black line), allows the calculation of more accurate values for the melting and crystallization temperatures and enthalpy values, without the influence of the thermal history. From this cycle, the values of melting $\left(T_{m 2}\right)$ and crystallization $\left(T_{c 2}\right)$ temperatures are: $219^{\circ} \mathrm{C}$ and $188^{\circ} \mathrm{C}$, respectively. The values of enthalpy associated with these transformations in cycle 2 are $\Delta H_{m 2}=51.33 \mathrm{~J} / \mathrm{g}$ and $\Delta H_{c 2}=42.66 \mathrm{~J} / \mathrm{g}$.

All the presented temperature and enthalpy values are summarized in Table 2, and work are used as a guide for establishing the thermal cycle for processing the composite material, since for a proper impregnation of the carbon fibers and molding capability, the matrix has to be in a soften state and the system cooling has to assure its crystallization.
The degradation of the matrix can be a limiting factor for the manufacturing process of composite materials. For this reason, Figure 2 presents the TG/DTG results for the polyamide sample heating cycle at three different rates considering the samples weight $(\%)$ as a function of temperature.

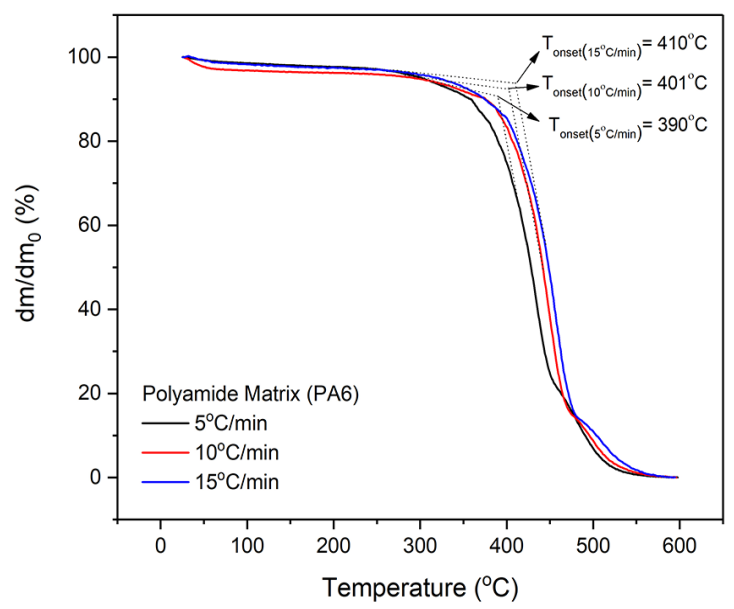

Figure 2. TGA weight results for the $10 \mathrm{mg}$ PA matrix samples under three different heating rates. (Bibliographic Source: Author.)

From Figure 2 it can be noticed that the most significant mass loss starts at approximately $350^{\circ} \mathrm{C}$ for all three heating rates, presenting a slight dislocation to the right due to the influence of higher heating rates. As described in the methodology section, the TGA results were then applied to Friedman's isoconversional kinetic model with the aim to estimate the degradation degree reached by the matrix by remaining at a certain temperature during a given time period.

Considering that the purpose of the degradation study presented hereby is to suggest a thermal cycle that can assure the final properties of the material, the degradation tolerance limit was settled as $5 \%$ and the prediction was then made for this degree, as presented in Figure 3. For the chosen limit, the coefficient of determination is about $85 \%$, providing a good estimated prediction of the degradation behavior for the polyamide matrix.

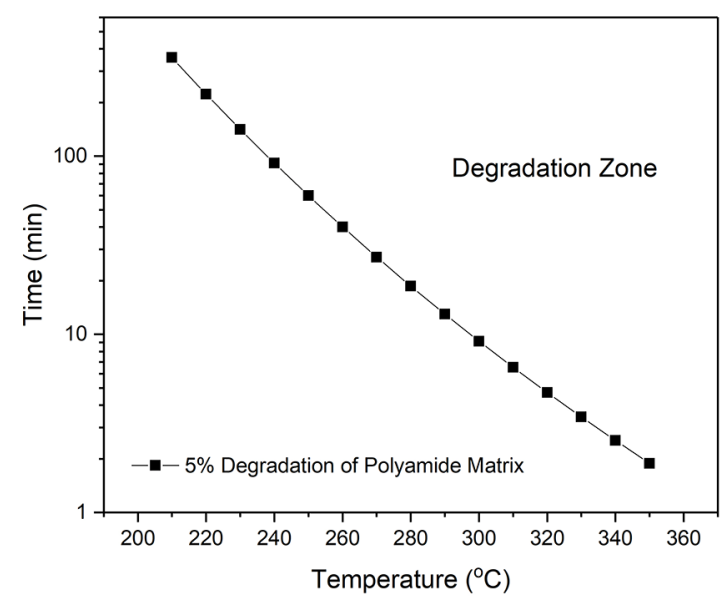

Figure 3. Prediction of the time as a function of temperature for $5 \%$ degradation degree of the PA matrix. (Bibliographic Source: Author.) 
Table 2. DSC summary table.

\begin{tabular}{cccccccc}
\hline \multirow{2}{*}{ Thermal Cycle } & \multirow{2}{*}{ Run } & \multicolumn{3}{c}{ Temperature $\left({ }^{\circ} \mathrm{C}\right)$} & \multicolumn{2}{c}{ Enthalpy $\left(\mathrm{J} . \mathrm{g}^{-1}\right)$} \\
& & Onset & Melt & Crystallization & End & $\Delta H_{m}$ & $\Delta H_{c}$ \\
\hline \multirow{2}{*}{$\mathbf{2}$} & 208 & 223 & - & 229 & 59.67 & - \\
& 2 & 184 & - & 177 & 161 & - & 60.32 \\
& 3 & 201 & 219 & - & 223 & 51.33 & - \\
& 4 & 192 & - & 188 & 180 & - & 42.76 \\
\hline
\end{tabular}

(Bibliographic Source: Author.)

Table 3. Time limit for $5 \%$ of PA matrix degradation in different isothermal temperatures.

\begin{tabular}{cc}
\hline Temperature $\left({ }^{\circ} \mathrm{C}\right)$ & Limit time for $5 \%$ of degradation $(\mathrm{min})$ \\
\hline 240 & 90 \\
250 & 60 \\
260 & 40 \\
270 & 30 \\
280 & 20 \\
\hline
\end{tabular}

(Bibliographic Source: Author.)

From Figure 3 it can be noticed that the CF/PA composites can be processed from $220^{\circ} \mathrm{C}$ (approximate melting temperature for the PA matrix) to $350^{\circ} \mathrm{C}$ (approximate degradation temperature for the matrix) without reaching no more than $5 \%$ of degradation if the processing time is under the limits. In order to preserve the properties of the thermoplastic matrix and avoid high manufacturing costs, it is better to select lower temperatures. Based on this consideration and taking into account the effects of heating distribution on larger components, the temperatures for the soaking of the matrix ranged from 240 to $280^{\circ} \mathrm{C}$, on steps of $10^{\circ} \mathrm{C}$ intervals.

Also, to isolate the temperature effect on energy absorption, the soaking time was selected to be a constant value of $20 \mathrm{~min}$ for all temperatures. This time selection was made regarding the time limits for $5 \%$ of matrix degradation at each temperature, as presented in Table 3, assuming that for $240^{\circ} \mathrm{C}$ no significant degradation degree is reached, while for $280^{\circ} \mathrm{C}$ the matrix is $5 \%$ degraded.

\subsection{CF/PA commingled fabric characterization}

Table 4 summarizes the fabric configuration and its construction. It also contains the values of carbon fiber yarn title and the fabric weight.

The Figures 4 and 5 reveal the micrographs of CF/PA fabric. It is a plain weave fabric with some polyamide yarn grouping dispersed in the carbon tow.

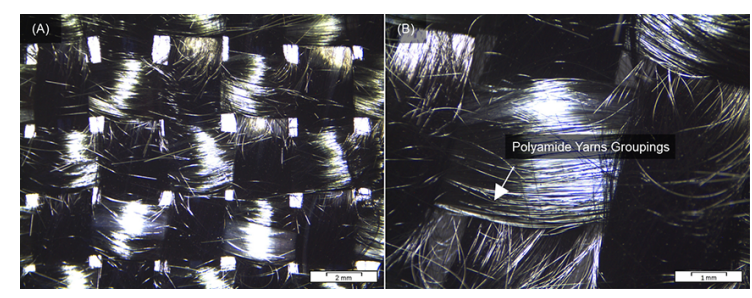

Figure 4. Stereoscope images of CF/PA commingled fabric features. (A) Plain weave commingled fabric. (B) Grouping of PA yarns. (Bibliographic Source: Author.)
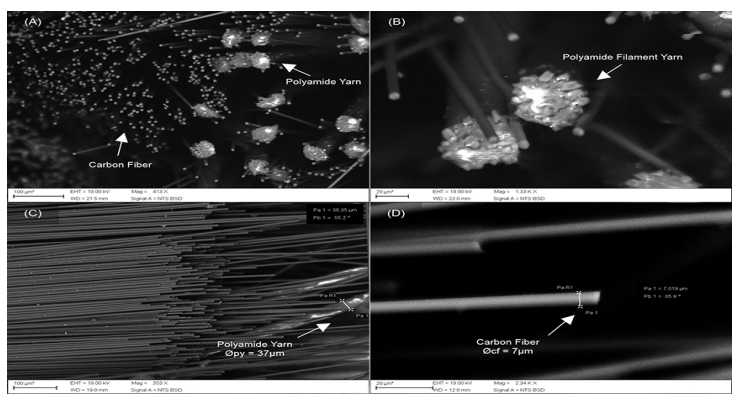

Figure 5. SEM images of CF/PA commingled tow. (A) Transversal section. (B) PA filament yarn detail. (C) Tow longitudinal section. (D) Carbon fiber diameter. (Bibliographic Source: Author.)

The Figure 4(A) presents the transversal section of the $\mathrm{CF} / \mathrm{PA}$ commingle tow and $(\mathrm{B})$ the multifilament polyamide yarn. The Figure 5 (A) and (B) shows the carbon fiber and the polyamide yarn diameters, $7 \mu \mathrm{m}$ and $37 \mu \mathrm{m}$ respectively.

\subsection{Impact and CAI tests}

The thermal processing cycle used to manufacture the flat panel for the impact and CAI tests is shown in Figure 6 . The processing temperatures were $240^{\circ} \mathrm{C}(1)$, $250^{\circ} \mathrm{C}(2), 260^{\circ} \mathrm{C}(3), 270^{\circ} \mathrm{C}(4)$ and $280^{\circ} \mathrm{C}(5)$.

Table 4. CF/PA preform datasheet.

\begin{tabular}{cccccccc}
\hline \multicolumn{2}{c}{ Sample } & \multicolumn{3}{c}{ CF/PA6 Commingled Tow } & \multicolumn{3}{c}{ CF/PA6 Commingled Plain Weave Fabric } \\
Mass $(\mathrm{g})$ & Mass $(\mathrm{g})$ & Length $(\mathrm{mm})$ & Title $(\mathrm{g} / \mathrm{km})$ & Average $(\mathrm{SD})$ & Mass $(\mathrm{g})$ & $\begin{array}{c}\text { Area }\left(\mathrm{mm}^{2}\right) \\
\text { Areal Weight } \\
\left(\mathrm{g} / \mathrm{mm}^{2}\right)\end{array}$ & $\begin{array}{c}\text { Average }(\text { SD) } \\
1\end{array}$ \\
\hline & 0.14 & 107.00 & 1275.14 & & 8.06 & 0.0132 & 610.61 \\
2 & 0.12 & 97.00 & 1276.08 & & 6.39 & 0.0105 & 611.48 \\
3 & 0.11 & 87.00 & 1279.89 & 1276.56 & 6.39 & 0.0104 & 611.54 \\
4 & 0.11 & 86.00 & 1279.65 & $(3.39)$ & 6.41 & 0.0105 & 610.48 \\
5 & 0.11 & 85.50 & 1272.05 & & 6.35 & 0.0104 & 610.58 \\
\hline
\end{tabular}

(Bibliographic Source: Author) 


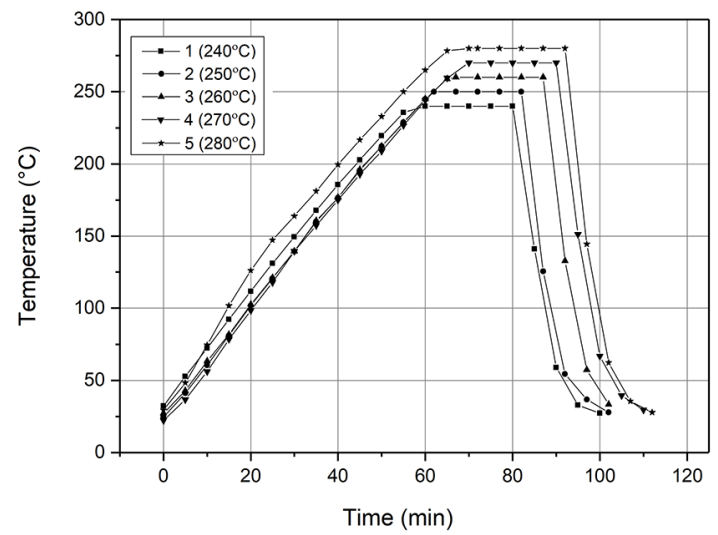

Figure 6. $\mathrm{CF} / \mathrm{PA}$ commingled composite flat panel processing cycles. (Bibliographic Source: Author.)

Figure 7 presents the CF/PA commingled composite specimens (A) and CAI C-scan results before (B) and after (C) the drop-weight impact test. The ultrasonic inspection reveals no voids and delamination on the samples before the impact event according the Figure 7 (B). The variation in color tone occurs due to the deviation of amplitude or depth of the signal emitted under the sample, and may be associated with surface irregularities, which inherent to the compression process. However, as can be seen on the Figure 7 (C), after the impact event, the extent of damage is clearly revealed.
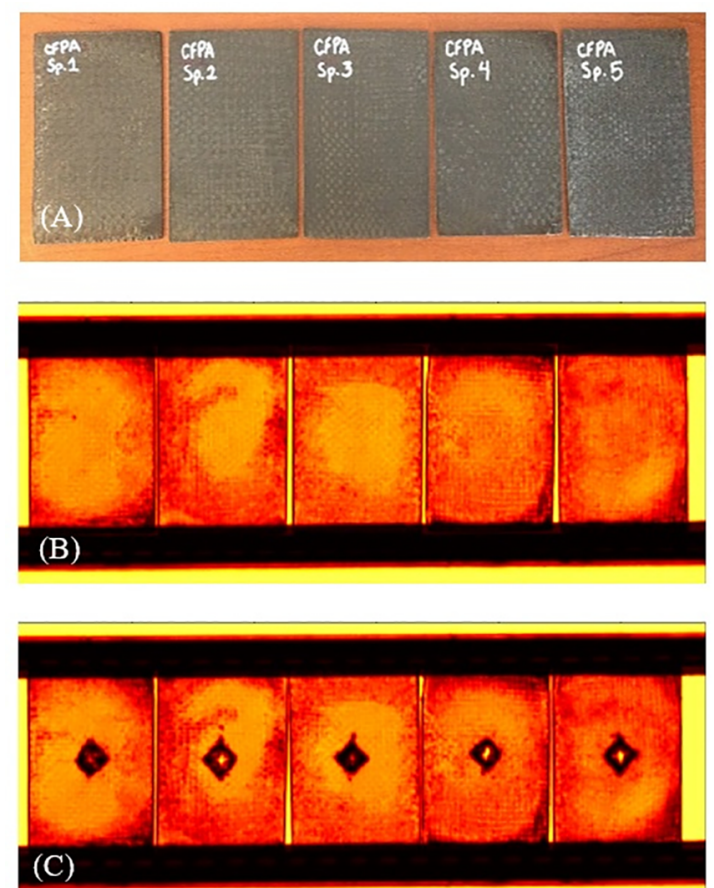

Figure 7. C-scan ultrasound inspection. (A) CF/PA commingled composite samples. (B) Before impact event. (C) After impact event. (Bibliographic Source: Author.)
The indentation damage combined large cracks with fiber breakage. The puncture caused a symmetric damage mark on the sample surface due to the out-of-plane drop-weight impact and the fabric plain weave [0/90] orientation layup.

The CF/PA commingled composite samples showed a reduction in energy absorption capacity $\left(-0,14 \mathrm{~J} /{ }^{\circ} \mathrm{C}\right)$ and increasing of the puncture deflection when the processing temperature was increased, as can be seen on Figure 8 and Figure 9 .

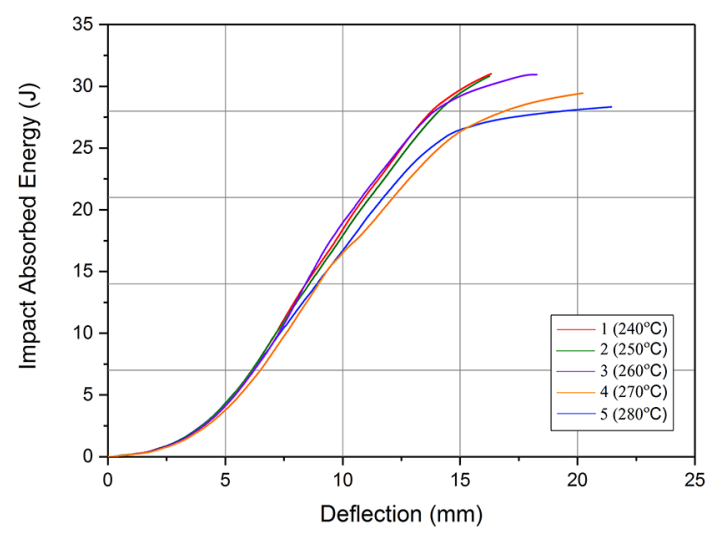

Figure 8. Absorbed energy on drop-weight test. (Bibliographic Source: Author.)

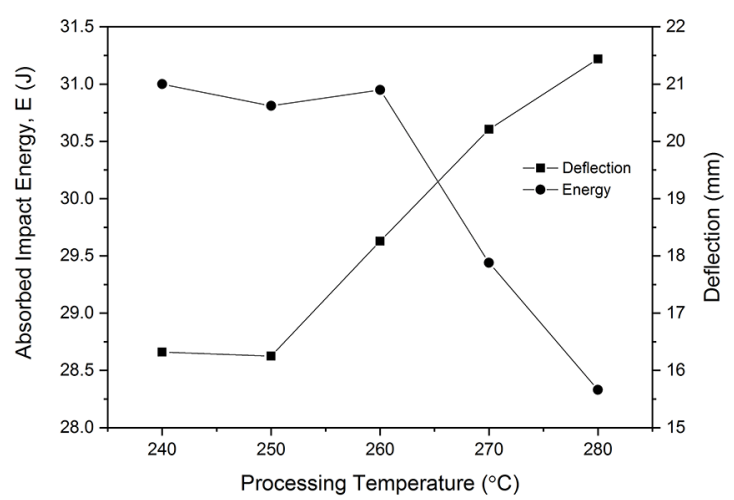

Figure 9. Energy absorption and damage deflection. (Bibliographic Source: Author.)

The CAI test revealed that the energy absorption capacity tends to reduce after the processing temperature at $260^{\circ} \mathrm{C}$ (Figure 10). The quasi-static test, as proved by $\dot{\epsilon}^{\prime}(t)=1124.45^{\mathrm{s}-1} \mathrm{33}$, involves the dynamic behavior of composite materials and failure theories to describe static and dynamic failure under multiaxial states of $\operatorname{stress}^{34}$. Generally, composite materials present limited plastic deformation ability. The CF/PA composite specimens have presented buckling during the load application, but no fracture. The energy was absorbed in creating large areas of damage with ensuing reduction of stiffness, as described on literature ${ }^{35}$. However, the prediction of the 
post-impact load of a damaged composite structure is a dificult assignment since the damage zone is generally complex in nature and difficult to characterize.

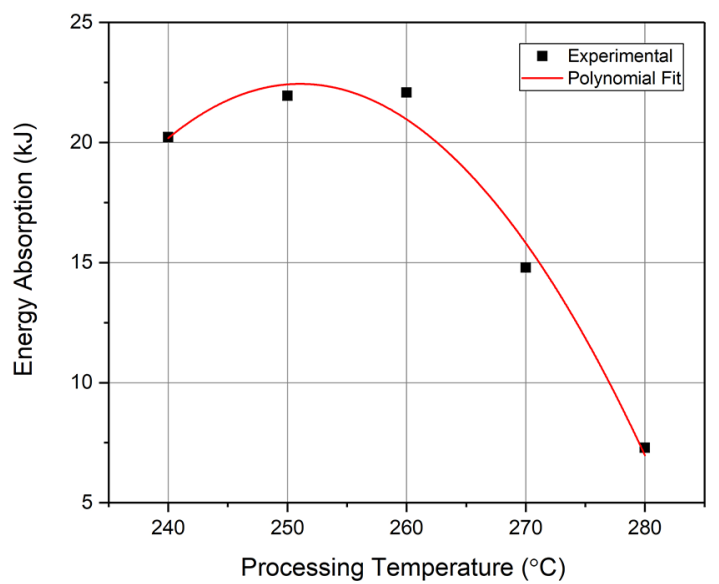

Figure 10. Energy absorption determinated by CAI test. (Bibliographic Source: Author.)

The polynomial fit $\left(\mathrm{R}^{2}=0.98349\right)$ reveals the tendency of reducing energy absorption capability when increasing the processing temperature of the thermoplastic composite, which is mainly associated with its degradation as a consequence of exposure to high process temperatures, affecting to some extent the performance and the life cycle of the obtained products $^{36}$.

Therefore, even though the increase in processing temperatures of thermoplastic composites is associated with some advantages, such as decreasing void fraction and strengthening the interface bonding ${ }^{37}$, the adverse effects of matrix degradation should be taken in account. In this way, it is reasonable to state that there might be an optimal processing temperature that can allow the proper impregnation of the fibers, avoiding the void formation without damaging the mechanical properties of the composite material. In the present study, the optimal processing cycle involves a soak time at $260^{\circ} \mathrm{C}$ of $20 \mathrm{~min}$.

\section{Conclusion}

The polymeric matrix thermo-oxidative degradation affects the energy absorption capacity of the thermoplastic commingled composite when the processing temperature exceeds the limits predicted in the degradation study. The optimal processing cycle occurs at $260^{\circ} \mathrm{C}$ for $20 \mathrm{~min}$. When it processed in temperatures above $260^{\circ} \mathrm{C}$, the $\mathrm{CF} /$ PA commingled composite reduces in $0.14 \mathrm{~J} /{ }^{\circ} \mathrm{C}$ the energy absorption ability (impact). Therefore, the $\mathrm{CF} / \mathrm{PA}$ commingled composite crashworthiness is impaired by thermo-oxidative degradation.
The prediction provided by thermo-oxidative degradation study is an important means to optimize the processing of thermoplastic composites, once it correctly provides the relation between processing time and temperature, indicating the degradation thresholds. The CF/PA composite energy absorption capacity is compatible with high performance composite materials when processed at temperatures below degradation limits.

\section{Acknowledgement}

TEXIGLASS and SAMPE Brazil director, Giorgio Solinas.

Dr. Dirk Heider, assistant director for technology of the Center for Composite Materials (CCM) - University of Delaware, USA.

CAPES (Coordination for the Improvement of Higher Education Personnel)

NTC (Composite Technology Center)

FINEP (Studies and Projects Financing Agency) for their financial support linked to the project number 0.1.13.0169.00.

\section{References}

1. Korich E, Belingardi G, Tekalign A, Roncato D, Martorana B. Crashworthiness Analysis of Composite and Thermoplastic Foam Structure for Automotive Bumper Subsystem. In: Elmarakbi A, ed. Advanced Composite Materials for Automotive Applications: Structural Integrity and Crashworthiness. John Wiley \& Sons; 2014. p. 129-147.

2. Ancelotti Junior AC, Pardini LC, Bezerra EM, Roach D. Use of the mar-lin criteria to determine the influence of porosity on the iosipescu and short beam shear properties in carbon fiber polymer matrix composites. Materials Research. 2010;13(1):6369.

3. Raponi OA, Raponi RA, Barban GB, Di Benedetto RM, Ancelotti Junior AC. Development of a Simple Dielectric Analysis Module for Online Cure Monitoring of a Commercial Epoxy Resin Formulation. Materials Research. 2017. In press.

4. Geiger O, Henning F, Eyrerer P, Brüssel R, Ernst H. LFT-D: materials tailored for new applications. Reinforced Plastics. 2006;50(1):30-35.

5. Souza BR, Di Benedetto RM, Hirayama D, Raponi OA, Barbosa LCM, Ancelotti Junior AC. Manufacturing and Characterization of Jute/PP Thermoplastic Commingled Composite. Materials Research. 2017. In press.

6. Chaudhari R, Reif M, Geiger O, Henning F, Diehl A, Terenzi A. E-Coat Sustainable Long-Fibre Thermoplastic Composites for Structural Automotive Applications. In: Conference on Innovative Developments for Lightweight Vehicle Structures; 2009 May 26-27; Wolfsburg, Germany.

7. Jacob GC, Fellers JF, Simunovic S, Starbuck JM. Energy Absorption in Polymer Composites for Automotive Crashworthiness. Journal of Composite Materials. 2002;36(7):813-850. 
8. Thornton PH. Energy absorption in composite structures. Journal of Composite Materials. 1979;13(3):247-262.

9. Duan S, Yang X, Tao Y, Mo F, Xiao Z, Wei K. Experimental and numerical investigation of Long Glass Fiber Reinforced Polypropylene composite and application in automobile components. Transport. 2017. DOI: 10.3846/16484142.2017.1323231

10. Brown KA, Brooks R, Warrior NA. The static and high strain rate behavior of a commingled E-glass/polypropylene woven fabric composite. Composites Science and Technology. 2010;70(2):272-283.

11. Bisagni C. Experimental investigation of the collapse modes and energy absorption characteristics of composite tubes. International Journal of Crashworthiness. 2009;14(4):365-378.

12. Wade B. Capturing the Energy Absorbing Mechanisms of Composite Structures under Crash Loading. [PhD Dissertation]. Seattle: University of Washington; 2014.

13. Solemanifar A, Wilkinson A, Kinjalkumar P. Damage Tolerance of Composites Containing Hybrid, Carbon-Innegra, Fibre Reinforcements. International Journal of Materials and Metallurgical Engineering. 2016;10(9).

14. Carruthers JJ, Kettle AP, Robinson AM. Energy Absorption Capability and Crashworthiness of Composite Material Structures: A Review. Applied Mechanics Reviews. 1998;51(10):635-649.

15. Van West BP, Pipes BP, Keefe M, Advani SG. The draping and consolidation of commingled fabrics. Composites Manufacturing. 1991;2(1):10-22.

16. Van West BP, Pipes BP, Advani SG. The consolidation of commingled thermoplastic fabrics. Polymer Composites. 1991;12(6):417-427.

17. Centro Ricerche Fiat. The research requirements of the transport sectors to facilitate an increased usage of composite materials. Part II: The Composite Material Research Requirements of the Automotive Industry. Turin: Centro Ricerche Fiat; 2004.

18. Batch GL, Cumiskey S, Macosko CW. Compaction of Fiber Reinforcements. Polymer Composites. 2002;23(3):307-318.

19. Ijaz M, Robinson M, Wright PNH, Gibson AG. Vacuum Consolidation of Commingled Thermoplastic Matrix Composites. Journal of Composites Materials. 2007;41(2):243-262.

20. Kamal MR, Sourour S. Kinetics and thermal characterization of thermoset cure. Polymer Engineering \& Science. 1973;13(1):59-64.

21. Silva JFMG. Pré-impregnados de matriz termoplástica: fabrico e transformação por compressão a quente e enrolamento filamentar. [PhD Dissertation]. Porto: Universidade do Porto; 2005.

22. Yousefpour A, Hojjati M, Immarigeon JP. Fusion Bonding/ Welding of Thermoplastic Composites. Journal of Thermoplastic Composites Materials. 2004;17(4):303-341.

23. Nikfar B, Njuguna J. Compression-after-impact (CAI) performance of epoxycarbon fibre-reinforced nanocomposites using nanosilica and rubber particle enhancement. II International Conference on Structural Nano Composites. IOP Conference Series: Materials Science and Engineering. 2014;64(1):012009.
24. Tenax T. HTS40 Catalogfecha. 2008. Available from: $<$ https:// www.rockwestcomposites.com/media/wysiwyg/Product Categories/Materials_Tools/13024-D_-_HTS40_E13-F13. pdf $>$. Access in 20/07/2017.

25. Concordia Fibers. Thermoplastic Fiber Options for Commingled Fiberfecha. Available from: <http://www.concordiafibers.com/ pdfs/Thermoplastic_Options.pdf $>$. Access in 21/07/2017.

26. ASTM International. ASTM-E1952 - Standard Method for Thermal Conductivity and Thermal Diffusivity by Modulated Temperature Differential Scanning Calorimetry. West Conshohocken: ASTM International; 2011.

27. Friedman HL. Kinetics of thermal degradation of char-forming plastics from thermogravimetry. Application to a phenolic plastic. Journal of Polymer Science: Polymer Symposia. 1964;6(1):183-195.

28. ASTM International. ASTM-D7136/D7136M-15 - Standard Test Method for Measuring the Damage Resistance of a FiberReinforced Polymer Matrix Composite to a Drop-Weight Impact Event. West Conshohocken: ASTM International; 2015.

29. Sierakowski RL. Strain Rate Effects in Composites. Applied Mechanics Reviews. 1997;50(12):741-761.

30. Daniel IM. Failure of Composite Materials under Multiaxial Static and Dynamic Loading. Procedia Engineerin. 2014;88:10-17.

31. ASTM International. ASTM-D7137/D7137M-12 - Standard Test Method for Compressive Residual Strength Properties of Damaged Polymer Matrix Composite Plates. West Conshohocken: ASTM International; 2012.

32. Bannach G, Perpétuo GL, Cavalheiro ETG, Cavalheiro CCS, Rocha RR. Efeitos da história térmica nas propriedades do polímero PET: um experimento para ensino de análise térmica. Química Nova. 2011;34(10):1825-1829.

33. Sierakowski LR. Strain Rate Behavior of Metals and Composites. In: Convegno IGF XIII Cassinofecha. Cassino; 1997. 28 p. Available from: $<$ http://www.gruppofrattura.it/ocs/index.php/ cigf/igf13/paper/viewFile/206/141>. Access in: 26/12/2017.

34. Hamouda AMS, Hashmi MSJ. Testing of composite materials at high rates of strain: advances and challenges. Journal of Material Processing Technology. 1998;77(1-3):327-336.

35. Manders PW, Harris WC. A parametric study of composite performance in compression-after-impact testing. SAMPE Journal. 1986;22(1):47-51.

36. Capone C, Di Landro L, Inzoni F, Penco M, Sartore L. Thermal and mechanical degradation during polymer extrusion processing. Polymer Engineering \& Science. 2007;47(11):1813-1819.

37. Gong Y, Yang G. Manufacturing and physical properties of all-polyamide composites. Journal of Materials Science. 2009;44(17):4639-4644. 